\title{
"Homem é tudo igual!": relações de gênero e economia dos afetos no arquipélago de Cabo Verde, África
}

"Men are all the same!": Gender relations and economy of affections in the archipelago of Cape Verde, Africa

Andréa de Souza Lobo e Francisco Paolo Vieira Miguel

\section{(2) OpenEdition Journals}

Edição electrónica

URL: https://journals.openedition.org/aa/4963

DOI: $10.4000 /$ aa. 4963

ISSN: 2357-738X

Editora

Programa de Pós-Graduação em Antropologia Social (UnB)

\section{Edição impressa}

Paginação: 192-212

ISSN: 0102-4302

\section{Refêrencia eletrónica}

Andréa de Souza Lobo e Francisco Paolo Vieira Miguel, «"Homem é tudo igual!": relações de gênero e economia dos afetos no arquipélago de Cabo Verde, África», Anuário Antropológico [Online], v.45 n.1 | 2020, posto online no dia 16 fevereiro 2020, consultado o 22 julho 2022. URL: http:// journals.openedition.org/aa/4963 ; DOI: https://doi.org/10.4000/aa.4963

\section{(c) (i) (9)}

Creative Commons - Atribuição-NãoComercial-SemDerivações 4.0 Internacional - CC BY-NC-ND 4.0 https://creativecommons.org/licenses/by-nc-nd/4.0/ 


\title{
“Homem é tudo igual!": relações de gênero e economia dos afetos no arquipélago de Cabo Verde, África
}

"Men are all the same!": Gender relations and economy of affections in the archipelago of Cape Verde, Africa

DOI: https://doi.org/10.4000/aa.4963)

\begin{abstract}
Andréa de Souza Lobo • Universidade de Brasília - Brasil
Professora do Departamento de Antropologia Social da Universidade de Brasília, Brasil. Pesquisadora da sociedade caboverdiana desde os anos 2000 com interesse nas temáticas do parentesco, dinâmicas familiares, gênero, diáspora e demais fluxos globais.
\end{abstract}

\section{Francisco Paolo Vieira Miguel • Universidade de Brasília - Brasil}

Professor substituto do Departamento de Saúde Coletiva e doutorando no Departamento de Antropologia Social, ambos na Universidade de Brasília, Brasil. Pesquisador em Cabo Verde e Moçambique sobre dinâmicas de gênero e homossexualidade.

Pretendemos, neste artigo, abordar os processos de construção de masculinidades no arquipélago de Cabo Verde tomando como via de acesso as relações afetivas hétero e homossexuais. Partindo da afirmação que está no título, ouvida com frequência tanto por mulheres heterossexuais quanto por homens gays, buscaremos demonstrar como os caminhos pelos quais a masculinidade se constrói nesta sociedade coloca as relações afetivas em um limiar delicado e permeado por símbolos negativos quando expressas por essas mulheres heterossexuais e homens gays: do não público, do não romântico, do não íntimo e do quase exclusivamente sexual. A partir dos dados etnográficos aqui analisados, desenvolvemos dois argumentos centrais para pensar masculinidades: 1) que o modus operandus dos homens com os gays não passa somente pela noção de vergonha, mas por um ethos masculino mais geral; 2) que não é suficiente pensar o papel do homem apenas como cônjuge, mas também como irmão e, principalmente, filho.
In this article, we intend to approach the processes of construction of masculinities in the Cabo Verde archipelago taking as access route the heterosexual and homosexual affective relationships. Based on the statement in the title, often heard by both heterosexual women and gay men, we will seek to demonstrate how the ways in which masculinity is built in this society places affective relationships on a delicate threshold permeated by negative symbols when expressed by them, heterosexual women and gay men: non-public, non-romantic, non-intimate and almost exclusively sexual. From the ethnographic data analyzed here, we develop two central arguments for thinking masculinities: 1) that the modus operandus of men with gays is not about shame, but for a more general male ethos; 2) that it is not enough to think of the role of man only as an husband, but also as a brother and, especially, a son.

Affection. Masculinity. LGBT. Gift. Conjugality. Genre. Intimacy. Cabo Verde. 


\section{Introdução}

Tendo como pano de fundo nossas pesquisas realizadas entre casais heterossexuais e homens gays no arquipélago de Cabo Verde ${ }^{1}$, buscaremos: 1) analisar a economia dos afetos das relações heterossexuais a partir da percepção de que há íntima relação entre afeto e troca no contexto familiar, ou seja, é pelas tensões e interconexões entre afeto, desejo e trocas materiais que se constroem intimidade e, sobretudo, o sentimento de "ser família", sendo o homem um ator que tensiona um sistema que tem por base a reciprocidade; 2) Nas relações homoeróticas, por sua vez, se a performance de gênero dos homens permanece semelhante àquela das relações heterossexuais, a impossibilidade tanto formal quanto prática de fazer cônjuges e família lança novos desafios para a análise. Tal tensão ganha outras proporções quando, às noções locais de conjugalidade, somam-se ideias românticas associadas a um dito "padrão europeu", que coloca as coisas nos seguintes termos: quando contrastados a uma imagem idealizada dos "homens da Europa", os cabo-verdianos "não servem".

Ao afirmarem que "homem é tudo igual", mulheres e gays parecem manifestar seu descontentamento com um modelo de masculinidade que permite aos homens viver relações poligâmicas (sem maiores repercussões de ordem moral), participar esporadicamente de uma lógica de reciprocidade local e se distanciar de um tipo de comportamento esperado em relações percebidas como ideais, ou seja, com apoio financeiro e afetivo mútuo, coabitação, cuidado com os filhos e algum "romantismo". De formas ora distintas ora semelhantes, mulheres heterossexuais e homens gays cabo-verdianos apontam para a ausência do homem no âmbito doméstico e sua relutância em aderir a valores associados a um ideal de relação afetivo-conjugal.

Antes de prosseguir, faz-se necessário precisar alguns pontos. Primeiro, estamos de acordo com diversos estudos que vêm apontando acertadamente que as construções, tanto das masculinidades quanto das feminilidades, são processos complexos nos quais as relações entre mulheres ou entre homens - e não apenas aquelas entre os sexos - têm tanto ou mais a revelar sobre tais identidades de gênero e a constituição de pessoas no mundo. Neste artigo, todavia, não vamos abordar esse debate, uma vez que nossa questão inicial tem como ponto de partida as relações amorosas e/ou sexuais. O movimento que pretendemos realizar aqui é o de pensar para além da reciprocidade familiar atualizada prioritariamente pelas mulheres, ou seja, pensar como relações de troca e reciprocidade, tão essenciais ao universo familiar cabo-verdiano, atualizam-se nas relações afetivo-sexuais entre homens e mulheres e entre homens héteros e homens gays. Portanto, o universo do masculino constrói-se, em nossa narrativa, pelas reflexões delas e deles, pares sexuais destes homens, com o intuito de colocar em questão algumas figuras arquetípicas que surgem neste contexto.

Isto nos leva ao segundo ponto. Uma das figuras que vamos abordar aqui está expressa no próprio título deste capítulo. $\mathrm{O}$ homem cabo-verdiano que não é sério, que "não presta” e que "é tudo igual” é certamente um tipo genérico, uma figura muito difundida, comum às diferentes classes sociais e fixada nas representações
1 As reflexões aqui sistematizadas são resultado do diálogo entre dois pesquisadores da sociedade cabo-verdiana. Andréa Lobo tem se debruçado sobre o entendimento das dinâmicas familiares em contextos de fluxos migratórios, de valores, discursos e objetos nos últimos 15 anos. Suas pesquisas refletem sobre as configurações das relações familiares em uma sociedade marcada pelo movimento como valor, a partir de uma perspectiva que busca resgatar a profundidade histórica dos valores familiares em diálogo. A etnografia dos significados e práticas em torno do casamento aqui esboçada é, portanto, resultado de dados oriundos de seus esforços de pesquisa. Já Francisco Miguel apresenta aqui dados e análises relativos à pesquisa de campo realizada no Mindelo, na Ilha de São Vicente, que resultou em sua dissertação de mestrado. A pesquisa etnográfica centrou-se na homossexualidade e na homossociabilidade masculinas e no recente movimento LGBT naquele país.

2 Agradecemos aos/às editoras/as e pareceristas do Anuário Antropológico pelos preciosos comentários que enriqueceram o texto. 
de gênero que veiculam. Como demonstraremos nas páginas que seguem, a "falta de seriedade" associada ao homem cabo-verdiano pode assumir significados distintos, mas costuma estar associada à sua forte inclinação para a "natureza" ou para o "costume" (ou tradição) das relações múltiplas, para alguns, denominada poligamia informal. Finalmente, este tipo pode assumir facetas rudes, associadas ao não romantismo, mas também pode atingir extremos que chegam à violência física e/ou simbólica ${ }^{3}$.

Por fim, é interessante chamar a atenção para a nossa proposta de abordar tais construções sobre o universo masculino através do olhar de seus pares sexuais e afetivos em relações hétero e homossexuais. Acreditamos que trazer a perspectiva dos gays não apenas complementa nossas imagens sobre o universo afetivo-sexual, mas amplia o debate para além de uma possível guerra entre os sexos (Castro, 2012). Salientamos, portanto, que nossa perspectiva não é de comparação, mas de complementaridade.

\section{Trocas, afeto e família}

Na introdução da coletânea Love in Africa, Jennifer Cole e Lynn Thomas (2009) chamam a atenção para a importância de colocar em contexto as análises sobre intimidade e amor, uma vez que as práticas de parentesco em constante mudança, as noções de gênero e as economias políticas estão intrinsecamente conectadas às formas como pensamos e construímos intimidades. Discursos contemporâneos, sentimentos e práticas de amor são produtos de processos históricos complexos e interseções (Cole; Thomas, 2009), e esses sempre devem ser observados por pesquisadores que se debruçam sobre o universo dos afetos e das relações íntimas.

A coletânea, em sua totalidade, responde a dois pontos importantes que permeiam a literatura africanista sobre família, parentesco e conjugalidades: a redução da intimidade africana ao sexo e a ideia de que emoções, intimidade e solidariedade familiar estariam (ou deveriam estar) em oposição aos intercâmbios econômicos, tratando-se de "mundos hostis" (Zelizer, 2005). Juntamente com outros estudiosos (Journet, 2005; Cole, 2005; Miller, 2010, Castro, 2012), os autores argumentam que, por mais que o senso comum ocidental oponha intimidades e trocas materiais, ambas estão profundamente conectadas em diversos cenários sociais, inclusive e sobretudo em contextos ocidentais.

$\mathrm{O}$ caso aqui analisado, o das relações no âmbito familiar em Cabo Verde ${ }^{4}$, parece ser mais um exemplo etnográfico que pode reforçar o argumento dos estudiosos aqui citados, pois reciprocidade e solidariedade são conceitos centrais para se compreenderem as relações familiares nesta sociedade. A troca recíproca de alimentos, bens, objetos e cuidados é um fator fundamental na construção da intimidade familiar. Tais relações são profundamente marcadas por laços sociais alimentados cotidianamente pela partilha e pelas trocas de coisas, valores e pessoas, e o sentimento de pertencimento está vinculado a um conjunto de referências comuns e à participação em uma comunidade de prática.

As relações familiares em Cabo Verde podem ser caracterizadas por um comprometimento mútuo, por contatos sociais regulares e por um fluxo intra e in-
3 Sobre a violência baseada no gênero em Cabo Verde, ver a excelente tese de Silva, 2018.

4 Cabo Verde é um arquipélago localizado no Atlântico e inabitado quando descoberto pelos portugueses em 1460. Sua efetiva ocupação se deu tardiamente e no contexto do comércio negreiro do continente africano para a Europa e as Américas. Seu processo de formação social é, portanto, resultado do encontro entre portugueses e africanos, dando origem a uma sociedade crioula marcada pela heterogeneidade. O país é historicamente caracterizado como uma sociedade de diáspora, dada a sua especialização histórica em exportar gente para o resto do mundo por meio da emigração. É nesse contexto que se estrutura um tipo de organização familiar com uma aparente ambiguidade - essencialmente patriarcal, mas com fortes características de matricentralidade (Monteiro, 1997; Braz Dias, 2000; Couto, 2001; Drotbohm, 2009; Fortes, 2013; Lobo, 2014a). 
ter-doméstico de benefícios materiais e não materiais (Lobo, 2011, 2014, 2014b; Defreyne, 2016). Tais elementos são importantes para a construção do sentimento de proximidade e atuam no fortalecimento de laços parentais pré-existentes. Os vínculos de consanguinidade não seriam, portanto, irrevogáveis, precisando ser atualizados cotidianamente por pequenos atos de partilha de objetos, alimentos e de cuidados.

Pensamos aqui nos termos sugeridos por Mauss (1974), no que diz respeito ao princípio da vinculação de pessoas e coisas nas trocas realizadas, ou seja, a partir do princípio da dádiva, no movimento de dar, receber e da obrigatoriedade ideal de retribuir. O mecanismo da troca na esfera familiar cabo-verdiana colocaria em evidência o modo pelo qual as pessoas se relacionam com aqueles considerados mais próximos: por meio dos bens (tangíveis ou intangíveis) trocados cotidianamente. Portanto, tal como desenvolvido no pensamento de Mauss ao tratar da dádiva, propomos pensar tais relações de troca como relações de aliança num sentido mais amplo.

De forma breve ${ }^{5}$, podemos destacar a mobilidade como um fator transversal que é parte da dinâmica familiar em diversos níveis: há constante partilha de coisas, alimentos, mensagens entre as casas, sendo esta última uma unidade central fortemente associada à mulher e às crianças; o homem, em sua posição de um próximo distante, incorpora uma dimensão do movimento como tensão, dada a incerteza sobre seu retorno (físico, financeiro, afetivo); finalmente, a emigração de homens e também mulheres, tão fortemente associada ao universo cabo-verdiano, intensifica não só as idas e vindas de pessoas, mas também trocas variadas e intensas que acabam por (re)produzir esse universo familiar em fluxos, em trocas (Lobo, 2014b ; Defreyne, 2016; Laurent, 2016).

As unidades domésticas, transversalizadas por esses múltiplos fluxos, são centradas na figura da mãe-avó. Apesar de operarem um ideal patriarcal, em que o homem exerce autoridade sobre o destino dos filhos e sobre o percurso de vida da mulher, na prática, elas têm um importante papel social e econômico, uma vez que os arranjos afetivos que predominam estimulam a circulação dos homens por várias unidades domésticas ao longo da vida adulta. O que queremos dizer é que as relações afetivas entre homens e mulheres, ainda que com filhos, têm por característica, num primeiro momento, a não fixação deste casal em uma união conjugal considerada estável: com residência compartilhada, divisão de tarefas no cuidado com as crianças e nas despesas financeiras.

Além disso, é frequente que o homem tenha simultaneamente relações sexuais e afetivas múltiplas, com mais de uma parceira, relações que também podem gerar filhos. Por fim, cabe ressaltar que os sentidos dados à masculinidade passam pela distância relativa do homem do universo doméstico, especialmente nos cuidados com as crianças. Tudo isso opera no sentido de conferir centralidade às mulheres no interior das famílias, posição reforçada pelas redes femininas de solidariedade e reciprocidade que conectam, no espaço e no tempo, casas e gerações por meio da partilha e da circulação de coisas, valores e pessoas.

Paralelamente, assim como as relações de parentesco devem ser obtidas,
5 Chamamos a atenção para o fato de que estas são características gerais apresentadas aqui no sentido de fornecer um panorama, um “tipo". Certamente, não é nossa intenção traçar características do que poderia ser uma "família cabo-verdiana”, pois esta só pode ser entendida no plural, uma vez que não é homogênea, devendo ser dada devida atenção a variáveis de classe social, capital social, sem falar nas importantes variações entre as ilhas. Para uma análise detalhada desse universo familiar a partir da Ilha da Boa Vista, ver Lobo, 2014. 
negociadas e alimentadas, as vidas dos indivíduos e suas posições no contexto familiar são decorrentes de escolhas, negociações e formas de participação nas trocas cotidianas, não devendo ser entendidas como devires inevitáveis e preestabelecidos dentro do sistema (Lobo, 2013). Captar este universo como um quadro composto por diversas possibilidades, em que as trajetórias dos indivíduos são múltiplas e suas posições são conquistadas a partir dos percursos de vida, é central para entender os lugares de homens e mulheres em relações afetivas e sexuais neste contexto, fazendo jus à heterogenia de suas experiências.

\section{Afetividades e sexualidades: um homem e muitas ausências}

É nesse cenário de partilha e trocas recíprocas que o homem é percebido em um lugar de proximidade distante, porque produtor de uma intimidade que carece de elementos essenciais para que seja plena, quando descrita pelo prisma de nossos interlocutores, mulheres hétero e homens gays. Conforme explicitaremos, os discursos desses dois grupos sobre o tal "homem cabo-verdiano" são coincidentes tanto em sua negativação quanto em sua própria vulnerabilidade diante dele. Porém, é importante notar que os desdobramentos das relações afetivo-sexuais entre homens-mulheres e "homens"-"gays"' têm implicações radicalmente distintas não somente em suas vidas, mas também nas possibilidades de construção de intimidades que ultrapassem o sexo.

É na tentativa de dar conta desta complexidade que convidamos o leitor para adentrar este universo em que o tecer e o romper da intimidade são constantes.

\subsection{O masculino na perspectiva das mulheres}

Isa estava contando que ela e Daniel estão separados porque ele só quer saber de paródia (festa, boemia). Isa diz que já está cansada e que não tem nenhuma vantagem em estar com Daniel, que ele não tem nada para lhe dar. Nilda comenta que a mulher tem que ser assim, que a maioria das muIheres que conhece, mesmo as mais jovens, não sabe se impor. São objetos sexuais de seus homens, que não as procuram para nada, só na hora que querem botar um cusinha na corpo ${ }^{7}$. Nilda diz não se sujeitar a isso, que só tem sexo quando quer e não quando ele tem vontade. Ela afirma que, para o homem cabo-verdiano, "nós, mulheres, só servimos para o sexo que eles querem, não ajudam com os filhos que fazem, não trazem dinheiro para casa, só querem saber de seus amigos, sua paródia, as outras pequenas e lembram da mulher somente quando querem se aliviar! Dar alguma coisa? Qual é! Só de vez em quando, muito raro... e ainda são brutos. E nós, muIheres de Cabo Verde, na maioria, permitimos que isso aconteça, gostamos e acabamos deixando que eles nos tratem assim!" Ela continua afirmando que o homem das ilhas gosta de mulher submissa, que não sai de casa e aceita tudo calada. Mas relata que hoje as coisas já mudaram um pouco. Me conta que, na ilha da Boa Vista, teria sido a partir de finais dos anos 1980 que as mulheres "começaram a acordar. Foi com a Malta Víbora, um grupo
6 Como veremos adiante, "homens" e "gays" são categorias localmente distintas, ainda que de um ponto de vista analítico ou linguístico, a primeira possa englobar a segunda.
7 A expressão em crioulo está relacionada a ter sexo, mas no sentido de aliviar o desejo. 
só de mulheres que trabalhava, tinha seu dinheiro e sua liberdade diante de seus homens. Elas faziam paródia, bebiam, iam para a festa sozinhas e foram muito criticadas na Boa Vista”. Isa interrompe Nilda, lembrando que ainda era menina naquela época, mas que as tinha como ídolos, como parâmetro da mulher que ela e outras meninas de sua idade gostariam de ser. "Antes delas a vida das mulheres era uma desgraça, porque o homem cabo-verdiano não serve... só mesmo para fazer filho e trazer problemas! Mas o que elas podiam fazer? E nós também, o que podemos fazer? Trocar? Como? Se eles são todos iguais? Eu e o Daniel mesmo, brigamos, separamos, mas quantas vezes isso já aconteceu? Eu, no fim, acabo cedendo... mas dessa vez...”. Ela mesma interrompe a narrativa e rimos as três, concordando implicitamente que ela vai ceder novamente às investidas do rapaz (Diário de Campo, 2005).

O trecho acima foi registrado por Andréa Lobo em uma tarde de conversa na qual Isa desabafava sobre as dificuldades do relacionamento com Daniel - pai de seu filho de 4 anos - e Nilda, mulher mais velha, a aconselhava a seguir sua própria vida. Segundo Nilda, Isa "não precisava de um homem como Daniel para nada" e isto sintetizaria diversos aspectos do universo afetivo e sexual entre homens e mulheres na perspectiva delas. O comportamento masculino é foco de uma insatisfação manifesta pela categoria ausência em diferentes níveis: física, pois ele está sempre em outro lugar que não a casa (ou seja, na paródia, na vida de festa, nos bares, na bebida alcoólica); material, uma vez que eles não contribuem regularmente com dinheiro ou bens; parental, tendo o homem uma relação distante com os "filhos que faz"; e emocional, ao reduzirem o afeto e a intimidade ao intercurso sexual.

$\mathrm{Na}$ perspectiva de diversas mulheres interlocutoras de pesquisa ${ }^{8}$, do homem cabo-verdiano não se pode esperar muita coisa. Utilizando a linguagem da reciprocidade familiar, o homem seria o polo negativo, uma vez que é "aquele com quem não se pode contar" no universo doméstico, pois seria de sua natureza estar na rua, transitar entre mulheres, se manter distante dos filhos e não garantir sua participação nas redes de trocas materiais e de ajuda mútua que "fazem família". Diante do cenário desenhado por elas, como se atualizariam as relações entre homens e mulheres? Como tais laços seriam tecidos no universo conjugal?

As relações afetivas entre homens e mulheres, especialmente entre os mais jovens, não são facilmente perceptíveis no cotidiano da vida pública. Andar de mãos dadas, abraçados ou a troca de carícias não são elementos que compõem o cenário do cotidiano, mesmo em bares ou discotecas. Saber quem tem com quem exige uma entrada nas redes locais de sociabilidade, conhecer as pessoas e fazer parte de esferas da vida social, tais como rumores, comentários e confidências sobre a vida amorosa de si ou do outro?.

Na perspectiva feminina, as relações, desde o primeiro momento, são marcadas pela ameaça real de que o companheiro também esteja saindo com outra ou outras, concomitantemente. Esta expectativa é foco de tensões e conflitos, sendo
8 As interlocutoras de pesquisa nas quais se baseiam as reflexões aqui esboçadas são mulheres de diferentes gerações - jovens, adultas e em idade madura, sobretudo de classes populares. Os dados foram coletados sobretudo junto a mulheres da llha da Boa Vista, entre os anos 2004 e 2005, mas complementados com pesquisas mais recentes na cidade da Praia.

9 Ter com é uma expressão local que pode equivaler a namoro ou até mesmo a uma relação mais duradoura, com filhos, implicando ou não coabitação. Quando tal relacionamento gera filhos, são utilizados os termos pai-de-filho ou mãe-de-filho para se referir ao companheiro ou companheira com quem se partilha a criança. Tais expressões são utilizadas referencialmente, ainda que a relação afetiva já tenha se dissolvido. O termo casamento só é utilizado quando este se configura legalmente, ou seja, no papel. 
vivida com ansiedade por parte das mulheres. Ter mais de uma pequena (namorada ou parceira sexual) é percebido como uma característica da "natureza do homem", algo inerente ao seu ser, um símbolo de masculinidade partilhado tanto por homens quanto por mulheres. Portanto, trata-se de algo esperado, mas não necessariamente aceito por elas, que utilizam diversas estratégias para afastar a(s) outra(s) e ter seu companheiro só para si.

Nesse universo de mobilidade masculina, quais as estratégias utilizadas pelas mulheres no sentido de manter um controle mínimo sobre a relação conjugal? É comum encontrarmos na literatura sobre conjugalidade cabo-verdiana a interpretação de que a capacidade do homem de prover a casa e os filhos é um fator importante na manutenção de uma relação conjugal (Braz Dias, 2000; Lobo, 2014; Grassi, 2003; Laurent, 2016). Porém, são igualmente comuns as histórias de mulheres que mantêm um relacionamento com um homem que não as suporte emocional e economicamente. Quando perguntadas sobre a razão de manterem uma situação de conflitos, por elas mesmas definida como "difícil", as respostas variam. Tal como implícito na conversa com Isa e Nilda, a sexualidade feminina deixaria a mulher vulnerável diante de uma conquista masculina. Além disso, há a noção de que os homens são todos iguais e que um bom companheiro, que preencha os requisitos do ideal de um bom homem, seria raro. Diante disso, há duas soluções possíveis: não ficar com ninguém ${ }^{10}$, pelo menos não com alguém fixo ou permanecer com o mesmo ${ }^{11}$, pois não adianta trocar.

Tal como expresso no discurso de muitas mulheres, a noção de "bom companheiro" parece opor-se a de "homem cabo-verdiano". Na busca por um tipo ideal que estaria no polo oposto, o bom companheiro seria um homem "como os europeus", que ajuda em casa, se envolve com os cuidados com os filhos, é carinhoso, romântico, não anda com outras mulheres e contribui financeiramente. No outro polo estaria o homem cabo-verdiano, "que não presta”, nunca está em casa, não dá atenção ou suporte emocional e financeiro aos filhos e mãe-de-filho, tem outras mulheres e é "bruto", ou seja, não é romântico"12.

Entretanto, a caracterização fortemente negativa destacada por elas parece ser contrabalançada quando adentramos no universo sexual. Quando o tema é sexo, os polos se invertem. Quando comparados com os europeus, os cabo-verdianos são considerados melhores parceiros sexuais. Tal atributo, ou seja, o fato de seus parceiros terem pegada, seria uma das fontes da vulnerabilidade feminina diante de suas investidas. Por fim, não podemos deixar de fora o amor, o gostar, o universo afetivo que está no centro da manutenção destas relações, e que a expressão em crioulo mi e dodu na bô (eu sou louca/o por você) sintetiza tão bem. Levar em conta esta dimensão é fundamental para retirar a carga instrumental que, de forma pouco sensível (para dizer o mínimo), os estudiosos sobre o tema acabam por reproduzir e reforçar.

Queremos chamar a atenção para o fato de que, apesar de as escolhas entre permanecer ou não em uma relação afetivo-conjugal serem racionalizadas a ponto de parecerem ser resultado de um cálculo estratégico de perdas e ganhos, há diversos fatores envolvidos - amor, química sexual, relações entre as famílias,
10 Tal como salienta a antropóloga cabo-verdiana Celeste Fortes, em seu artigo intitulado "Casa sem homem é um navio à deriva", esta não parece ser uma opção ambicionada neste universo (Fortes, 2015).

11 Lembramos que não estamos argumentando a favor da fixidez dos pares sexuais ou afetivos. Mulheres e homens trocam ou podem trocar de parceiros ao longo da vida. Estamos aqui no universo de caracterização, por tais mulheres, do universo masculino e de sua relação com ele.

12 Certamente, a brutalidade pode atingir níveis de violência física. Infelizmente, não são raros os relatos de mulheres vítimas de violência doméstica. Para mais detalhes, ver, dentre outros, Silva e Vieira, 2016. 
prestígio, o valor de um homem no universo doméstico, a figura de um pai para o filho, entre outros.

Fortes (2015), no artigo já mencionado, também evoca tanto as razões de ordem emocional, afetiva e subjetiva quanto a importância estratégica do homem para a vida social de uma mulher, afinal, um homem em casa impõe respeito. "Fica evidente que a necessidade da presença do homem em casa, a existência de filhos e a pressão familiar, que vem especialmente de familiares próximos, como a mãe, podem ser apontadas como razões para que o casal entre num ciclo de conflitos e reconciliações" (Fortes, 2015, p. 159).

Por todas essas questões, tais mulheres vivem um dilema: o de permanecer ou não em relações que elas mesmas classificam como problemáticas ou fonte de sofrimento. Um caminho analítico possível seria o da histórica competição de modelos operando na sociedade crioula de Cabo Verde (Trajano Filho, 2009). No contexto familiar, esses padrões em concorrência informariam a dinâmica de vida de mulheres, homens e crianças por meio das noções de estrutura e desestrutura familiar. Romper com comportamentos familiares tidos como desestruturantes coloca-se como um desafio para governos e movimentos feministas locais e como um imponderável para mulheres jovens, que se veem em um conflito constante entre discursos e práticas em competição.

Entretanto, talvez seja mais produtivo pensar para além dos modelos em competição, tal como elaborados por Trajano Filho (2009). Uma vez que assumimos a centralidade das trocas nas dinâmicas familiares, o que propomos é pensar a partir desse lugar ambíguo do homem para a reprodução (ou não) do "fazer família”. Para avançar neste sentido, é necessário que retomemos a dimensão contextual mais ampla, dos valores e normas que dão sentido a estas relações, mas também das condições materiais de vida nas quais elas se enraízam. Afinal, como é ser homem jovem em um cenário de alto índice de desemprego, de acesso limitado aos recursos econômicos e de prolongada dependência econômica da família de origem ${ }^{13}$ ?

Explorar essa combinação do valor das trocas, das retribuições e da reciprocidade - inclusive sob forma de presentes e dinheiro - com o acesso limitado e instável aos recursos econômicos, pode nos ajudar a pensar sobre as tensões no universo familiar aqui apontadas. Como já observado na seção anterior, nossa interpretação sobre os dados nos leva a refletir sobre uma ausência relativa desse homem que, a depender do momento em sua trajetória individual e familiar, da classe social, do acesso a recursos e do papel social que desempenha nas unidades domésticas das quais é membro (como filho, irmão, sobrinho, marido etc.), pode se posicionar mais próximo ou mais distante. Pois ter família é um valor na construção de sua masculinidade, sendo ele um ator também central no "fazer família”. É aí que trazemos para análise um terceiro elemento que se agrega ao homem e à mulher, fundamental para esse universo familiar heterossexual e para os sentidos de masculinidade e feminilidade: os filhos.

Conforme já sistematizado no item anterior, ter um filho é fator essencial para os sentidos de ser adulto, para se apresentar como homem ou mulher e para a atualização das lógicas de reciprocidade entre pessoas, famílias e unidades domés-
13 Alguns trabalhos sobre jovens em contextos africanos têm colocado questões semelhantes a esta. Para os interessados em respostas possíveis, ver Ratele (2014) e Uchendu (2008). 
ticas. Ter algo em comum é a base para a proximidade - partilha, troca de bens, serviços, emoções, reprodução e significado constituem a essência para que as relações entre parentes sejam construídas. A família seria, então, o terreno ideal para a reciprocidade e, se esta é quebrada, as relações de parentesco esvaziam-se de tal forma que podem se tornar apenas memória.

A relação do homem neste contexto é caracterizada por um distanciamento relativo. A conclusão lógica nos levaria, portanto, a confirmar um dado presente nas políticas familiares em Cabo Verde: que a família cabo-verdiana sofre da síndrome da ausência paterna. Porém, antes de concluirmos em tais termos, preferimos abordar a relação entre pais/filhos (e, consequentemente, entre mães-de-filhos/ pais-de-filhos) a partir de outro prisma, como uma relação triangulada pela mãe ou irmã do pai. Nosso argumento é o de que as crianças podem contrapor a tendência masculina de afastamento do novo grupo familiar. Tal aproximação se daria pela relação entre a criança e as mulheres da família paterna, visto que uma mulher pode abrigar filhos de um homem parente seu: mães podem cuidar dos filhos de seus filhos ou mesmo as irmãs abrigam filhos de seu irmão. Avós e tias paternas seriam, portanto, mediadoras entre pai e filhos.

Num contexto em que a relação afetiva entre mãe-de-filho e pai-de-filho é, em um primeiro momento, marcada por alguma instabilidade, por meio da circulação, a criança oriunda dessa relação cria um elo entre as famílias, elo este que pode garantir que o homem retorne ciclicamente àquela mulher, acabando por se fixar em uma relação conjugal que pode culminar no casamento. Neste sentido, as crianças, além de produzirem laços de filiação, fazem aliança, uma vez que constituem elos para a atualização da reciprocidade entre seus pais. Assim, as relações afetivas entre um homem e uma mulher acabam por se fortalecer tanto pelo nascimento de um filho quanto pela relação entre os grupos familiares que esta criança faz acontecer cotidianamente.

Por fim, salientamos que a relação de relativa distância não retira do pai o desejo de ter filhos. Ter um filho é um valor importante no universo masculino, assim como ter uma mulher (ou várias) (Lobo, 2010; 2014a). Ambos são símbolos de masculinidade exibidos constantemente nas rodas de conversas entre homens. Porém, enquanto as mulheres valorizam a ideia de estar próximo, os homens, enquanto pais-de-filho, se envolvem com o universo doméstico por meio de um pertencimento distante. $\mathrm{E}$ falar nesses termos tem implicações importantes, pois relativiza a noção de ausência masculina do universo doméstico.

É nesse jogo entre proximidade e distanciamento que o homem se insere no universo de trocas que "fazem família". Enquanto companheiro-pai, seu lugar é ambíguo pois, ao mesmo tempo em que sua presença é desejada e fundamental para o ser mulher, ser mãe e ser família, as formas pelas quais sua masculinidade é construída tornam sua presença não somente distante, mas fonte de angústia, ansiedade e sofrimento para estas mulheres (e seus filhos). É no equilíbrio da proximidade-distância do homem que estas mulheres ambicionam construir uma intimidade afetivo-sexual que não se reduza ao sexo, mas que se insira no complexo sistema de solidariedade e reciprocidade que "faz família" nesta sociedade. 
Retomando a conversa com Isa, quando ela reflete sobre as vantagens de manter a relação com Daniel e chega à conclusão de que, para além da troca sexual, não há vantagem alguma, chamamos a atenção para o fato de que as trocas sexuais são estruturalmente inseridas em transações diversas, inclusive econômicas. No sentido de evitar reiterar interpretações equivocadas das dicotomias entre uma "boa sexualidade", desinteressada, e uma "má sexualidade" - esta última mediada por "interesses" materiais e, portanto, moralmente comprometida -, inserimos o universo das relações entre homens e mulheres em um contexto mais amplo, trazendo os valores, as normas e as práticas que informam as relações familiares. Com isso, demonstramos que a contradição ou a incompatibilidade que se supõe existir entre a esfera dos sentimentos e do amor, de um lado, e a dos interesses materiais, de outro, deve ser percebida em contexto e verificada etnograficamente. Esta vigilância faz-se necessária para evitarmos a armadilha de uma singularização ou tipificação absolutamente equivocada de uma suposta sexualidade africana (Castro, 2012) ou outra qualquer.

Para completar o argumento aqui proposto, resta-nos analisar como se dão essas dinâmicas no universo homoafetivo masculino, ressaltando as semelhanças e as diferenças com o que vimos até aqui.

\subsection{O homoerotismo masculino no arquipélago}

Inicialmente, é importante estabelecer uma diferença fundamental de princípios e de desejos entre as relações hétero e homoafetivas no universo social pesquisado em Cabo Verde ${ }^{14}$. Para tanto, faz-se necessário compreender como a homossexualidade masculina é vivida majoritariamente neste país. Abrimos a seção com o depoimento de Bela, uma traveste ${ }^{15}$ da Ilha de São Vicente:

Nós, em Cabo Verde, nós somos gays, nós somos travestes, mas nunca nos envolvemos com gays. Nós gostamos de nos envolver com homem. Homem que não gosta de levar na bunda. Homem. Nós gostamos de homem, não gostamos de gay, diferente dos estrangeiros. No estrangeiro, gay gosta de gay. Mas nós, não, nós somos diferentes.

Neste relato, a traveste Bela trata em termos locais do sistema hegemônico de sexualidade masculina em Cabo Verde, que separa "homens" e "gays". Tal sistema é análogo àquele descrito pelo antropólogo Peter Fry para as classes populares da periferia de Belém, no Brasil, pesquisadas na década de 1970 (Fry, 1982). Em Cabo Verde, os comportamentos sexuais de homens e gays são, ideal e respectivamente, os de "ativo" e "passivo". Assim como ocorre na relação com as mulheres, os homens não gays também agem de forma estereotipicamente masculina, enquanto os gays e as travestes, analogamente, articulariam muitos dos signos femininos dispostos em sua cultura. Obviamente, há deslocamentos e recitações criativas desses signos de masculinidade/feminilidade nos corpos dos sujeitos, assim como as performances sexuais tampouco são sempre cartesianas (Butler, 1999, p. 89). Em outras palavras, este modelo nunca se realiza perfeitamente, mas opera como
14 Aqui, teremos como interlocutores homens jovens, de 25 a 35 anos, de classes popular e média, originários, em sua maioria, da Ilha de São Vicente. 15 A identidade traveste diz respeito não somente $a$ classificações por intensidades de masculinização/feminilização dos corpos, mas também reverbera posições de classe. No geral, porém, as travestes são aquelas que nasceram com órgãos genitais masculinos, são pessoas mais pobres que, ao desejarem ser mulher, mantêm seus corpos ao máximo feminilizados e que advogam, por vezes, esta identidade para si. A grafia distinta pretende marcar não somente uma distinção fonética da língua crioula em relação à língua portuguesa, mas também demarcar que a identidade traveste se diferencia culturalmente das travestis brasileiras, por nunca terem seus corpos transformados por próteses de silicone e por tratamentos hormonais, tecnologias nem sempre desejáveis, não disponíveis localmente e inviáveis do ponto de vista econômico para elas. Para conforto do leitor, daqui em diante aparecerá sem grifo. 
uma norma, e é neste sentido que os modelos de sexualidade propostos por Fry (1982) nos auxiliam aqui.

Compreendido isto, importa informar que nem o casamento gay nem a união civil entre pessoas do mesmo sexo são legalizados no país, e a homossexualidade entre os homens cabo-verdianos é majoritariamente vivida de maneira não conjugalizada e, sobretudo, dificilmente de maneira romantizada, seja nas classes populares seja nas médias. Mesmo havendo queixa e angústia de muitos sujeitos gays em relação a esta falta de romantismo dos homens, a homossexualidade masculina é vivida especialmente por meio de encontros sexuais pontuais, diferente dos casos selecionados no trabalho da antropóloga cabo-verdiana Cláudia Rodrigues (2010), nas classes altas da capital Praia, regidos pelo que Peter Fry (1982) já chamou de "modelo simétrico".

Dessa forma, se nas relações heterossexuais haveria a potência de construção da família pela via da filiação, o mesmo não acontece no universo homoerótico masculino por nós pesquisado. Em um sistema heteronormativo como o cabo-verdiano, as relações heterossexuais têm a potência de propiciar alianças intergrupais e familiares que vão para além do casal, ao passo que a relação homossexual se restringe exclusivamente ao par. Nas relações homoeróticas não costuma haver sogras, cunhadas e demais afins. Assim, diferente das relações heterossexuais, nas quais ainda que haja a distância relativa do homem e certa escassez na demonstração de afetos nos termos esperados pelas mulheres, nas relações homoeróticas de Cabo Verde, a conjugalidade e as relações de aliança que dela derivam são uma impossibilidade dada, como nos relata Lunga, um interlocutor gay de 34 anos ouvido por Miguel (2016):

- E aí... Bom, a relação sexual acontece, mas existe alguma cumplicidade, existe alguma relação afetiva, de ciúme, de saudade...?

Hum... não. Se existir, acho que é imediatamente aniquilado por eles mesmo. Porque a pressão é tanta... Eles, não sei, é muito confuso... Não dá mesmo, não dá. Eu diria que não existe qualquer tipo de afetividade, não... Não existe. Se começar a despontar alguma coisa, como te disse, é anulado imediatamente. Tem nada. Não tem como, mesmo. Comigo e com os outros também. É claro que existem outros casos de alguns que conseguem levar, não sei o que... Mas porque eles investem do seu tempo e insistem e insistem e sofrem, sofrem, sofrem, sofrem, sofrem... Mas eu não! Eu costumo dizer que eu gosto muito, muito de mim mesmo.

A "casualidade" apontada por Lunga e por outros sujeitos gays cabo-verdianos, também entendida como certa falta de compromisso, é algo diagnosticado desde os primeiros cortejos, no mandar bocas, na performance "agressiva" ou "estúpida" dos rapazes, passando por um desprezo no cotidiano, até a recusa definitiva de dar prosseguimento à relação. Pelo que vimos até aqui, já é possível especular que o comportamento dos rapazes não gays, se analisado em contexto juntamente 
com as relações heterossexuais, pode remeter não somente a uma sexualidade envergonhada, mas também a um ethos masculino cabo-verdiano mais amplo, que tende a escapar do modelo de conjugalidade romântica e moderna. Isto não quer dizer, no entanto que, entre amigos heterossexuais, relações de afeto e companheirismo não existam. Pelo contrário, alguns autores demonstram que essas relações podem ser íntimas e marcadas por sérios compromissos interpessoais de vida e de morte (Bordonaro, 2012; Massart, 2013).

Contudo, em nossas conversas com sujeitos gays, a mágoa da impossibilidade de efetivação de um modelo específico de relação romântica era uma constante. Os avisos dos rapazes não gays, "você não me conhece, e eu não te conheço", logo após o ato sexual fugaz nas ruas; as bocas agressivas como "paneleiro"16; o desaparecimento dos rapazes quando os sujeitos gays tentam travar algum contato; a frequente hesitação e recusa quanto ao beijo na boca na hora do sexo; a negação da relação por parte dos rapazes quando estão com amigos em local público; tudo isso vai criando uma relação entendida como carente de reciprocidade e, consequentemente, gera-se um sentimento de angústia entre os gays do Mindelo.

Ainda que os rapazes não gays mantenham relações sexuais com os gays, eles simplesmente não concebem a possibilidade de conjugalização dessas relações. Casar-se ou até mesmo namorar, na maioria das vezes, não faz parte de sua gramática relacional. Mesmo entre os mais jovens, que já instauram alguma mudança, ao se identificarem como "bissexuais" (e, portanto, diferente dos outros, assumem uma identidade não heterossexual), não se escapa dos jogos afetivos e eróticos tradicionais.

A entrevista realizada mais recentemente com o porteiro Joaquim - um rapaz “não gay” de 32 anos e que tem duas mães-de-filho - confirma o quadro geral:

- Você já morou junto com um homossexual?

Eu? Nunca... com mulher já, já morei com duas mulheres.

- Por quê?

Eu sempre convivi com mulher... com homossexual, eu nunca convivi, assim, de sentar, conversar...nunca tive...

- Só sexo?

Então, isso foi lá na (Ilha do) Sal... Eu conheci um italiano em um hotel, e aí ele ficava insistindo. Eu dizia para ele para me deixar sossegado porque eu tinha minha mulher, e ele ficava insistindo, e aí aquela coisa foi. Ele era cliente do hotel, então ele ficava indo e voltando. Às vezes, ele vinha e ficava uns quatro ou cinco dias, ia e passava uns quatro meses e voltava... E aí ele ficava sempre no mesmo hotel, e a gente ficava conversando. E aí a gente teve uma coisa... mas ninguém veio a saber... Mas continuamos e continua-
16 Mandar boca é agredir ou provocar verbalmente alguém. Um dos xingamentos mais agressivos dirigidos ao homossexuais é "paneleiro". Para mais detalhes sobre a dinâmica dessa e de outras abordagens entre homens no contexto da llha de São Vicente, ver Miguel, 2016. 
mos e foi indo... Aí, depois eu saí daquele hotel, e a gente perdeu o contato.

Assim como pode se evidenciar no depoimento de outros rapazes não gays (Miguel, 2016), Joaquim também é exclusivamente ativo nas relações sexuais, recusando-se a tocar as genitálias de seus parceiros sexuais masculinos, alegando nunca os beijar na boca e evitando andar juntos com eles publicamente.

Da mesma forma como indagávamos às mulheres, perguntávamos, afinal de contas, por que os gays se envolvem com rapazes não gays e se frustram, se está posto culturalmente que a linguagem da relação está permeada por reclamações de "machismo", "estupidez", "ignorância”, "grosseria" etc. Suas respostas revelam que o jogo afetivo e erótico entre duas pessoas demanda delas uma semântica compartilhada, em que ambas precisam criar expectativas convergentes, trocar artefatos e gestos, coincidir significados e comunicar-se. Nesse sentido, se não se compartilham, em geral, sonhos de um futuro juntos e uma eventual filiação compartilhada, o que se troca na intimidade entre homens e gays em Cabo Verde?

Em um ensaio reflexivo sobre o trabalho de campo, o antropólogo Stephen O. Murray (1996), que desenvolveu vasta pesquisa sobre homossexualidade em países da América Latina, afirma que nem sempre a razão para que uma pessoa se engaje em um ato sexual é propriamente o desejo ou suas preferências, podendo também ser a ascensão social, os possíveis benefícios financeiros ou outros motivos (Murray, 1996, p. 244). Ao analisar relações heterossexuais no Mali, Castro (2012) sustenta que as transações sexuais são estruturadas tanto por ligações amorosas e/ou sexuais quanto por questões materiais e/ou econômicas, não havendo necessariamente contradição ou incompatibilidade neste fato. Agregando ao argumento de ambos, podemos afirmar que, eventualmente, nas relações homoeróticas aqui analisadas também se trocam ingressos de festas, bebidas, cigarros e dinheiro. Mas além de bens materiais, acrescentamos também: troca de performances de gênero e posições sexuais que sejam atrativas para ambos; empréstimo de corpos para se experienciarem desejos eróticos específicos e desprovidos do risco da reprodução e pequenos afetos. Tudo isto pactuado a partir do compartilhamento da confiança sobre o anonimato daquela relação arriscada socialmente (Miguel 2014, p. 157-158).

Em outras palavras, fica claro que, para além dos homens, tanto os sujeitos gays quantos as mulheres, ainda que avaliem negativamente o tratamento recebido, partilham e corroboram, de alguma forma, as normas sociais de gênero e sexualidade que mantêm o sistema operando. Entre os sujeitos gays, por exemplo, fica evidente que eles demandam dos rapazes uma postura hipermasculina, idealizada, uma masculinidade hegemônica. E que se não performatizada pelos rapazes - como quando revelam sua preferência por serem passivos no ato sexual - é denunciada e ridicularizada pelos próprios gays (Miguel, 2016). Contudo, essas normas de gênero - especialmente esta masculinidade hegemônica - têm sido questionadas pelos movimentos feministas locais, como veremos a seguir. 


\section{Masculinidade hegemônica e sua domesticação}

De acordo com Kopano Ratele (2008), especialista sul-africano no campo dos estudos sociais sobre homens e masculinidades, a primeira onda de pesquisas sobre este tema no continente apontou recorrentemente para uma "crise de masculinidade", que se explicaria em função de acontecimentos históricos recentes como o colonialismo e, posteriormente, o neoliberalismo, que teriam desestabilizado os papéis de gênero tradicionais dos homens africanos (Ratele, 2008, p. 20-22) ${ }^{17}$. Outra corrente de estudos, afirma o autor, busca apontar para a dimensão violenta da masculinidade africana, o que justificaria o cenário frequente de conflitos e guerras no continente, razão pela qual ela deveria ser transformada (Ratele, 2008, p. 20$)^{18}$. Ratele exemplifica as duas correntes por meio da análise de um mesmo caso hipotético, qual seja, o de uma adolescente africana que é engravidada por um homem mais velho que não assume a criança.

Para a primeira corrente, tal situação seria decorrente dos males da pós-colonialidade e do capitalismo, que incapacitam este homem a exercer plenamente a função social tradicional de pai provedor. A segunda privilegia as razões jurídicas, culturais e econômicas e enfatiza a assimetria de poder entre homens e mulheres. Segundo Ratele, nos estudos sobre homens africanos, há certa tendência a se enfatizar seu deslocamento em relação às posições tradicionais de gênero com o advindo do colonialismo. Análises "simpáticas" aos homens - é como Ratele classifica este primeiro grupo - têm ecoado em cenários africanos, pois a ideia de uma angústia masculina derivada da perda da masculinidade real tem ressonância em um continente profundamente crítico às políticas imperialistas ocidentais.

Todavia, nos aproximamos da proposição de Ratele quanto a um "estudo crítico" dos homens. Seu objetivo é levar a sério a angústia masculina, mas ponderar que outros grupos (como as mulheres e os LGBT) seriam ainda mais oprimidos num regime de hegemonia masculina ${ }^{19}$. Além disso, politizar as masculinidades permite perceber não somente a variedade, mas as hierarquias entre elas (Ratele, 2008, p. 32), o que ajuda a compreender a revolta dos homens jovens que não conseguem gozar do privilégio patriarcal e que dele também se sentem excluídos (Ratele, 2014, p. 125).

Em Cabo Verde, as etnografias sobre as relações de gênero oferecem um cenário em que se opera um sistema estruturado de forma binária e sexista (Rodrigues, 2010, p. 105), enquadrando em seu interior os diversos exercícios de sexualidade que fogem ao conjunto de práticas e identidades consideradas "heterossexuais". Vários autores têm apontado para uma tendência "patriarcal" como característica importante da sociedade cabo-verdiana (Lobo, 2014; Rodrigues, 2010; Miranda, 2013; Fortes, 2015), ainda que outros dela se apropriem para empreender sua desconstrução teórica e prática, a partir da exposição do papel de destaque das mulheres (Rodrigues, 2007). A “dominação masculina” é evidente para alguns autores (Rodrigues, 2010, p. 105), enquanto outros têm tratado da reprodução de uma "masculinidade hegemônica" que também seria incorporada pelas mulheres cabo-verdianas (Massart, 2004).

Tendo em vista o "patriarcado" como suposto sistema de organização social
17 Ao analisar os grupos thugs de Cabo Verde, o antropólogo Bordonaro também aposta na explicação de crise da masculinidade (Bordonaro, 2012, p. 132). Fazendo uma análise diacrônica das performances de gênero de cinco homens praienses, Massart parece seguir o mesmo caminho, apesar de negar o conceito de "crise" (Massart, 2013, p. 311), assim como Stefani (2015, p. 22).

18 Entre esses mesmos grupos thugs, porém, essa lógica da violência masculina adjetivada de "africana" fica clara nos depoimentos dos interlocutores de Bordonaro (2012, p. 21). Ver também os estudos de Lima (2010, 2012).

19 Segundo Ratele (2014, p. 116), o medo de ser percebido como gay faz com que alguns homens africanos exagerem todas as regras tradicionais de masculinidade, o que concorreria para explicar o surto de homofobia recente no continente (p. 118). 
em Cabo Verde, nele se encontram referências sobre uma suposta predisposição êmica que naturalizaria a poligamia masculina (Rodrigues, 2007, p. 141; Vasconcelos, 2012, p. 60; Massart, 2004; Miranda, 2013, p. 17), além de uma divisão do trabalho com ênfase no gênero (Lobo, 2007, p. 71; Massart, 2004), na qual se destaca a distância relativa dos homens do universo doméstico (Lobo, 2014, p. 67-68,75; Rodrigues, 2007, p. 140-141; Massart, 2004), e uma masculinidade heterocentrada (Rodrigues, 2010, p. 105), que se define pela hétero e hiper sexualidade (Rodrigues, 2007, p. 139-141).

Além disso, em Cabo Verde, a masculinidade é construída, sobretudo, através da exibição pública da virilidade (Miranda, 2013, p. 77), performada por meio de ações teatralizadas, simulações, exibição pública, discussões e a depreciação do feminino (Miranda, 2013, p. 81). Todavia, para alguns, devido às novas dinâmicas culturais e econômicas em Cabo Verde, esta masculinidade estaria passando por uma crise nos dias de hoje (Bordonaro, 2012, p. 132; Miranda, 2013, p. 106; Stefani, 2015, p. 21). Outros autores a negam, demonstrando as continuidades da "masculinidade hegemônica" local, tomando como pressuposto a melhor aceitação da homossexualidade pelos homens em geral (Massart, 2013, p. 311).

Dado tanto o cenário de relações de gênero quanto a economia dos afetos hétero e homoeróticos em Cabo Verde que aqui resumimos, Massart coloca a seguinte questão: "Pode algo alterar a masculinidade hegemônica?" (Massart, 2013, p. 298 $)^{20}$. Alguns movimentos sociais locais têm buscado domesticar as masculinidades que julgam nocivas para o desenvolvimento de relações mais simétricas de gênero, pautadas em outros tipos de trocas recíprocas. Em outras palavras, organizações civis locais, interessadas em questões de gênero, família e sexualidade e patrocinadas por instituições estrangeiras, vêm tentando implementar novos discursos sobre a masculinidade no intuito de sensibilizar os homens cabo-verdianos para a igualdade de gênero e para "novas" (ou "estrangeiras" e supostamente mais adequadas) formas de ser "homem".

Entre as instituições cabo-verdianas de promoção de novas sensibilidades masculinas, as de maior destaque atualmente são: a ONU Mulheres Cabo Verde, o ICIEG, a VerdeFam, a Morabi, a Associação Gay Cabo-verdiana e a Laço Branco. No entanto, enfocaremos apenas aquela que, ainda que compartilhe as premissas do pensamento feminista de todas as demais, é constituída e formada majoritariamente por homens. Nossa escolha recai sobre o fato de ela configurar-se como lócus privilegiado para a análise dos discursos de um grupo não hegemônico no campo dos debates feministas, ou seja, de homens debatendo questões de gênero e masculinidade.

Em parceria com as instituições acima mencionadas, surgiu em 2009, de forma inovadora, a Laço Branco Cabo Verde (LBCV) que, de acordo com sua carta de princípios, pretende "promover a igualdade e a equidade do gênero; combater todas as manifestações de violência [...]; promover e estimular a assunção plena dos direitos e deveres próprios da paternidade”, entre outros objetivos. Clovis Isildo Silva, casado e pai de quatro filhos de mães distintas, é deputado nacional e atual presidente da organização. Ele tem lutado contra o que chama de "mas-
20 E ele mesmo responde, afirmando que observou mudanças geracionais em relação ao gênero, em Cabo Verde, nas últimas décadas. Os homens, observa, estão um pouco mais preocupados com os filhos, mais carinhosos com os amigos e com as mulheres e até aceitando melhor a homossexualidade, algo antes “impensável” (Massart, 2013, p. 313). Mas é especialmente entre as mulheres que o autor percebe maiores transformações. As razões? Mudança nos discursos sobre direitos; maior igualdade e responsabilidade entre os casais, que ganharam visibilidade com a abertura local da mídia televisiva aos canais estrangeiros, principalmente brasileiros, portugueses e cabo-verdianos, muito assistidos pelas mulheres. Fora isso, a escolarização das mulheres, a abertura do comércio e a maior possibilidade da imigração feminina também foram fatores importantes na transformação dessas mulheres (Massart, 2013, p. 299, 307). 
culinidade tóxica" em Cabo Verde, marcada pela violência dos homens contra as mulheres, pelo distanciamento do lar e da família, pela homofobia e pela ode às drogas e ao alcoolismo ${ }^{21}$.

Na página da LBCV no Facebook é possível acompanhar a atuação da ONG. Sempre de forma muito pedagógica, a organização promove cursos de formação sobre gênero para líderes comunitários, agentes públicos, presidiários e estudantes, assim como realiza exposições artísticas relativas aos temas do universo masculino - como o futebol - e campanhas virtuais de conscientização sobre esses e outros temas caros ao grupo. O que gostaríamos de destacar é o engajamento dessa organização na desconstrução de certas noções de masculinidade em Cabo Verde, que pressupõem uma hierarquia do masculino sobre o feminino, buscando substituí-las por outras que coincidem com o que se tem defendido no campo progressista dos países ocidentais e que atualmente parece ganhar terreno em solo cabo-verdiano.

Nesse sentido, trazemos alguns dados relativos a essa prática de "sensibilização". Em 2017, no programa "Em Debate” da Televisão de Cabo Verde (TCV), sobre o tema da violência doméstica, o presidente da LBCV, Clovis Silva, exemplificou como, de maneira concreta, deveria ocorrer essa transformação na sociabilidade masculina, tratando especificamente da hegemonia da poligamia como ideal de masculinidade local:

[...] E o exercício dessa masculinidade, ela [sic] precisa ser despida desses problemas. Ou seja, nós precisamos falar com os homens para que se sintam à vontade... para que eu não tenha que ter frustrações, de fato, de falar com outros homens e dizer "Eu só tenho uma mulher. Tu tens várias, mas não é mais feliz do que eu sou"22.

Em relação à tão debatida ausência paterna dos lares cabo-verdianos, a LBCV defendeu a importância da presença masculina, em sua cartilha sobre "paternidade responsável", apelando para a sua "insubstituível, inigualável e intransferível" responsabilidade ${ }^{23}$.

Com grande abertura também para a questão das sexualidades não hegemônicas, a LBCV faz frequentes defesas das relações homoafetivas no país e dos direitos daqueles e daquelas que as vivenciam no cotidiano, divulgando em sua página do Facebook eventos ligados às organizações LGBT locais, bem como defesas explícitas dos direitos dessa comunidade nos meios de comunicação. Em entrevista concedida à UNITEL, o argumento de seu presidente é o de que deve haver possibilidades legítimas de exercício da masculinidade fora da heteronormatividade.

De uma forma ou de outra, o que esta organização e as demais que mencionamos anteriormente parecem buscar é a construção de relações de gênero mais simétricas. O desafio a se enfrentar é o de não privilegiar um modelo de família e de relações conjugais associadas a um ideal de modernidade que, ainda que mais simétrico e menos violento para mulheres e gays aqui analisados, quando veiculado como um "padrão a seguir", surge como alternativa (e em oposição) às
21 Entrevista concedida à UNITEL: https://www. facebook.com/Uniteltmais/ videos/1617960878245089/ 22 Fonte: http://www.rtc.cv/ tcv/index.php?paginas $=47 \&$ id cod=59821 (00:14:42-00:15:03). 23 Fonte: https://www. facebook.com/LBCaboVerde/ posts/10156204521591874 
dinâmicas locais percebidas como negativas e com viés de classe. Ou seja, um padrão de homem e de família simplificadamente atribuído à população de baixa renda. Se levado nesses termos, um resultado possível desse debate seria a (re) produção de novas (e velhas) desigualdades - de classe, de gênero e de geração.

Tal como observado na literatura histórica sobre o arquipélago, a relação pendular dos cabo-verdianos entre modelos é constitutiva dessa sociedade crioula em sua própria formação. A transição entre formas europeias e africanas enquanto polos de um espectro, a sociedade escravocrata daí surgida e a emigração estruturante que a constitui até os dias de hoje conferem a esta formação social contornos muitas vezes associados ao par ideal e prática - com alguma frequência observa-se a família cabo-verdiana descrita como aquela que persegue constantemente um ideal de estrutura nuclear, neolocal e de igualdade entre os gêneros, mas que se efetiva na prática com base em um modelo patriarcal, desigual e violento para mulheres (e gays). Em alguma medida, nossos interlocutores de pesquisa partilham e reproduzem essa fórmula, ao classificarem o homem cabo-verdiano por seus atributos negativos, pela ausência. Em última instância, ele seria a fonte dos males da família, e os demais, suas vítimas.

Contudo, como bem sabemos, os universos sociais estão longe de ser lineares, e se deslocarmos nosso olhar para a centralidade das trocas materiais em um contexto familiar no qual as relações de filiação têm preponderância sobre as conjugais, o lugar desse homem se complexifica. Este mesmo homem, normalmente definido pelas ausências e pela construção da intimidade somente pela via do sexo, ao assumir o papel social de filho ou irmão, parece ocupar um novo lugar. Ressaltando a centralidade dos laços de filiação nessa sociedade, cabe a um filho homem prestar assistência, ajuda e dar suporte material à mãe, bem como cuidar de sua irmã. Lobo (2014a) enfatiza que, se olharmos para a figura masculina em seus múltiplos papéis sociais e em diferentes fases do ciclo doméstico, captaremos a complexidade de seu lugar nos processos de reprodução social. Portanto, ao se deslocar a ênfase êmica da ausência masculina para uma estrutura familiar que privilegia a filiação sobre a conjugalidade, é possível reinterpretar o lugar do homem no contexto familiar, sem desconsiderar as dores, os ressentimentos e as ansiedades de mulheres heterossexuais e de homens gays.

Quando ampliamos a lente para o universo homoerótico masculino, o quadro se torna ainda mais interessante, pois o que se constata é que a intimidade construída entre os parceiros passa por outras vias que não as da formação de um tipo familiar e que tampouco há a perspectiva de descendência. Se nas famílias heterossexuais, tenham a forma que tiverem, há alianças entre famílias e os parceiros podem proporcionar um ao outro o status de "mãe-de-filho" e "pai-de-filho", no caso dos parceiros homoeróticos, em Cabo Verde, não se vislumbra mais do que a efetivação de um desejo erótico. Assim, o que se troca nas relações homoeróticas, de fato, são experiências sexuais não normativas, são confidências quanto aos desejos individuais socialmente reprimidos, além de objetos materiais. Esta é a razão pela qual os sujeitos gays por nós ouvidos vivem relações mais precarizadas do que as mulheres em Cabo Verde, se vistas sob o prisma local romântico/ 
moderno que projetam e compartilham sobre suas vidas.

Retomando a noção de economia dos afetos, que norteia o nosso argumento neste artigo, o que ela nos permite é ampliar o escopo da análise quando observamos os universos de sexualidade e intimidade, questionando sobre as trocas envolvidas, sejam elas materiais, corporais, afetivas ou emocionais. Consequentemente, tal prisma nos permite refletir sobre as dependências oriundas de tais trocas que, certamente, geram custos, ganhos e perdas cruzados. Se compreendemos as trocas íntimas e afetivas a partir da noção de economia dos afetos, ou seja, como interações sociais que podem fazer parte de diferentes registros geralmente apreendidos separadamente: sexual, familiar, conjugal, amigável (Zelizer, 2005); estaremos abertos a melhor compreender os universos relacionais de homens, mulheres e gays no contexto aqui analisado, ou seja, de relacionamentos íntimos que se baseiam em graus variados na confiança (que geralmente é assimétrica), mas que implicam e pressupõem um grau mínimo de reciprocidade.

Sendo assim, nossa ênfase analítica na centralidade das trocas para construção de formas de conjugalidade e de afetividade constrói-se numa tentativa de nos distanciarmos de análises que esperam que a ausência de traços comumente associados ao universo familiar deva resultar em ausência de intimidade. Os estudos antropológicos que constroem imagens salientando a complexidade das atitudes, experiências e expectativas dos contextos de filiações, conjugalidades e afetos, têm demonstrado não ser este o caso. Tais contextos são arenas de disputas, conflitos, tensões e poder, mas também de afetos, sentimentos e escolhas. Abordá-los a partir de uma perspectiva nuançada de suas práticas permite que nos afastemos do risco de analisá-los como modelos alternativos, visão que pressupõe a concordância de que há um modelo familiar e de gênero "normal" ou hegemônico dos quais os demais se distanciam. 


\section{Referências}

BAUMAN, Zygmunt. Amor líquido: sobre a fragilidade dos laços humanos. Rio de Janeiro: Zahar, 2004.

BORDONARO, L. Masculinidade, violência e espaço público: notas etnográficas sobre o Bairro Brasil da Praia (Cabo Verde). Tomo - Revista do Programa de Pós-Graduação e Pesquisa em Ciências Sociais, Universidade Federal de Sergipe (UFS), n. 21, p. 101136, 2012.

BRAZ DIAS, J. Entre partidas e regressos: tecendo relações familiares em cabo verde. Dissertação (Mestrado em Antropologia) - Universidade de Brasília, Brasília, 2000.

BUTLER, J. Gender trouble: feminism and the subversion of identity. New York: Routledge, 1999.

CASTRO, Julie. "Les filles sont trop matérialistes": tensions et soupçons dans les transactions sexuelles au Mali. In: FASSIN, D.; EIDELIMAN, J.-S. (Eds.). Économies morales contemporaines. Paris: La Découverte, 2012. p. 309-330.

COLE, J. Love, money, and economies of intimacy in Tamatave, Madagascar. In: COLE, J.; THOMAS, L. M. (Eds.). Love in Africa. Chicago: University of Chicago Press, p. 109-134, 2009.

CONNELL, R. W.; MESSERCHMIDT, M. Hegemonic masculinity: rethinking the concept. Gender \& Society, n. 19, p. 829-895, 2005.

COUTO, C. Estratégias familiares de subsistências rurais em Santiago de Cabo Verde. Lisboa: Instituto da Cooperação Portuguesa, 2001. (Coleção Teses).

DEFRAYNE, E. Au rythme des tambor: ethnographie des mobilités des gens de Santo Antão (Cap-Vert, Belgique, Luxembourg). 333f. 2016. Thèse (Docteure en Sciences Politiques et Sociales: Anthropologie) - Faculté des Sciences Économiques, Sociales, Politiques et de Communication, Université Catholic de Louvain, OttigniesLouvain-la-Neuve, 2016.

DROTBOHM, H. Horizons of long-distance intimacies: reciprocity, contribution and disjuncture in Cape Verde. History of the Family, n. 14, p. 132-149, 2009.

FORTES, C. M t'studa p'm k ter vida k nha mãe tem. Género e Educação em Cabo Verde. Revista Ciências Sociais Unisinos, v. 49, n. 1, p. 80-89, 2013.

FORTES, C. "Casa sem homem é um navio à deriva": Cabo Verde, a monoparentalidade e o sonho de uma família nuclear e patriarcal. Anuário Antropológico, v. 40, n. 2, p. 151-172, 2015.

FRY, P. Da hierarquia à igualdade: a construção histórica da homossexualidade no Brasil. In: FRY, P. Para inglês ver: identidade e política na cultura brasileira. Rio de Janeiro: Zahar, 1982. p. 87-115.

GRASSI, M. Rabidantes: comércio espontâneo transnacional em Cabo Verde. Lisboa: ICS, 2003.

JOURNET, N. L' argent en famille. Terrain, Anthropology \& Sciences Humaines, n. 45, p. 5-12, 2005.

LAURENT, P.-J. Famílias sob influência de leis migratórias dos países de acolhida: comparação das migrações cabo-verdianas nos Estados Unidos e na Itália. In: LOBO, A.; BRAZ DIAS, J. (Orgs.). Mundos em circulação: perspectivas sobre Cabo Verde. Brasília; Praia: ABA Publicações; EDUni-CV; Letras Livres, 2016.

LIMA, R. Thugs: vítimas e/ou agentes da violência? Revista Direito e Cidadania, v. 30, p. 
191-220, 2010. (Edição Especial: Política Social e Cidadania).

LIMA, R. Bairros desafiliados e delinquência juvenil: o caso do bairro da Achada Grande Trás, mimeo., 2012.

LOBO, A. Tão longe e tão perto. Emigração feminina e organização familiar: Boa Vista-Cabo Verde. In: GRASSI, M. I. Género e migrações cabo-verdianas. Lisboa: Imprensa de Ciências Sociais, 2007.

LOBO, A. Making familiar organization in Cape Verde. Vibrant - Virtual Brazilian Anthropology, v. 8, n.2, p. 196-219, 2011.

LOBO, A. Tão longe tão perto: famílias e "movimentos" na ilha da Boa Vista de Cabo Verde. Brasília: ABA Publicações, 2014a.

LOBO, A. "Just bring me a little letter": the flow of things in Cape Verde transnational family relations. Etnográfica, v. 18, n. 3, p. 461-480, 2014 b.

LOBO, A. Crianças em cena: sobre mobilidade infantil, família e fluxos migratórios em Cabo Verde. Revista Ciências Sociais Unisinos, v. 49, n. 1, p. 64-74, 2013.

MAUSS, M. Ensaio sobre a dádiva. Forma e razão da troca nas sociedades arcaicas. In: Sociologia e Antropologia. v. II. São Paulo: Edusp, 1974. [Edição original: 1923-24].

MASSART, G. Masculinités pour tous? Genre, pouvoir et gouvernmentalité au Cap-Vert. Le foyer dans la spirale de l'ouverture et du changement à Praia. Revue Lusotopie, v. XII, n. 1-2, p. 245-262, 2004.

MASSART, G. The aspirations and constraints of masculinity in the family trajectories of Cape Verdean men from Praia (1989-2009). Etnográfica, v. 17, n. 2, p. 293-316, 2013.

MIGUEL, F. "Levam má bô”: (homo)sexualidades entre os sampadjudus da Ilha de São Vicente de Cabo Verde. Dissertação (Mestrado em Antropologia Social) - Universidade de Brasília, Brasília, 2014.

MIGUEL, F. Levam má bô: (homo)sexualidades masculinas em um arquipélago africano. Curitiba: Prismas, 2016.

MILLER, D. Stuff. Cambridge: Polity Press, 2010.

MIRANDA, J. M. V. Constituição de masculinidades num contexto de crise do pescado: uma abordagem etnográfica em Rincão, Santiago, Cabo Verde. Dissertação (Mestrado em Ciências Sociais) - Universidade de Cabo Verde, Praia, Cabo Verde, 2013.

MURRAY, S. O. Male homosexuality in Guatemala: possible insights and certain confusions from Sleeping with the Natives. In: Out in the Field. Chicago: University of Illinois Press, 1996. p. 236-260.

RATELE, K. Hegemonic African masculinities and men's heterosexual lives: some uses for homophobia. African Studies Review, v. 57, n. 2, p. 115-130, 2014.

RODRIGUES, C. A Homoafectividade e as relações de género na Cidade da Praia. Dissertação (Mestrado em Ciências Sociais) - Universidade de Cabo Verde, Praia, Cabo Verde, 2010.

RODRIGUES, I. P. As mães e os seus filhos dentro da plasticidade parental: reconsiderando o patriarcado na teoria e na prática. In: GRASSI, M.; ÉVORA, I. Género e Migrações Cabo-Verdianas. Lisboa: Imprensa de Ciências Sociais, 2007. p. 123-146.

SÁEZ, J.; CARRASCOSA, S. Por el culo: políticas anales. Madrid; Barcelona: Editorial Egales, 2011.

STEFANI, S. Thug life e ativismo social: construções de masculinidades de protesto nos bairros populares da Cidade da Praia (Cabo Verde). Novos Debates, v. 2, n. 1, p. 19-28, 2015. 
Andrea de Souza Lobo e Francisco Paolo Vieira Miguel

SILVA, C. F.; VIEIRA, M. S. (Orgs.). Género e sociabilidades no interior de Santiago, Cabo Verde. Praia; Porto Alegre: Edições Uni-CV; Editora da UFRGS, 2016.

SILVA, C. F. A Rede Sol e a Lei Especial contra Violência Baseada no Gênero: processos institucionais e narrativas de mulheres e homens em situação de violências conjugais em Cabo Verde. Tese (Doutorado em Antropologia Social) - Universidade Federal de Santa Catarina, 2018.

TRAJANO FILHO, W. The conservative aspects of a centripetal diaspora: The case of the Cape Verdean Tabancas, Africa, v. 79, n. 4, p. 520-542, 2009.

UCHENDU, E. Masculinities in Contemporary Africa. Dakar: CODESRIA, 2008.

VALE DE ALMEIDA, M. A chave do armário: homossexualidade, casamento, família. Florianópolis: Editora da UFSC, 2010.

ZELIZER, V. Intimité et Économie. Terrain, Athropologie \& Sciences Humaines, n. 45, p.13-28, 2005. 